\title{
The Zero Discharge of Urban Waste Water
}

\author{
Manuel Jiménez Aguilar* \\ Instituto Andaluz De Investigación Y Formación Agraria, Spain
}

*Corresponding author: Manuel Jiménez Aguilar, Instituto de Investigación y Formación Agraria y Pesquera (IFAPA), Consejería de Agricultura y Pesca, Junta de Andalucía, Camino de Purchil, Granada, Spain

Submission: 傮 August 09, 2018; Published: 眥 August 15, 2018

\section{Opinion}

GA few days ago the European Community imposed a fine on Spain because some of its municipalities do not adequately purify their waste water. In my opinion and in the light of current knowledge the existence of sewage treatment stations in some cases is an error. In most of the Andalusian villages the cultivation fields are below the urban areas, so in case of drought the wastewater can be reused in the fields. Thus in the metropolitan area of Granada, some of the most fertile soils (the well-known Vegas of the rivers) owe their existence since the Middle Ages to be able to reuse this wastewater for irrigation. The soil absorbs all the nutrients and at the same time acts as a purifying system. Through a system of irrigation channels and a network of irrigators this water is reused and purified. A system that has worked for more than ten centuries is absurd that it is now considered a problem and fined for it. It is better to reuse water than to purify it.

On the other hand, the dumping and transport of urban waste water is the source of the spread of contamination to rivers, lakes and the sea. No spill no pollution. A dry treatment of urban wastewater could significantly reduce pollution and water consumption. If urine and faeces are recycled at source, it could save water (about 20 litres per person per day) and treatment costs of wastewater would be reduced. Urine is a resource available in all human societies. By recycling urine in every home we can recover nutrients, reducing the need for artificial fertilizers.

Urine held in a slightly acidic medium as olive Oil Waste Waters (OOW) prevents decomposition of the urea, avoiding losses of ammonium-nitrate and increasing proportions of phosphorus and potassium, so that the urine-OOW mixtures could be considered a fertilizer N-P-K. The urine should be recycled for use as a source of urea and phosphorus, liquid fetilizer, $\mathrm{CO} 2$ absorbent, obtaining hydrogen and other uses. Stools should be treated dry with solid organic waste to produce compost and solid fertilizers. First we must recycle and in my personal opinion and then establish purification systems. In my personal opinion the system of treatment and purification of urban wastewater used so far in developed countries should be reviewed. As far as possible, the wastewater treatment system should be changed to recover urine and feces as sources of nutrients and new resources. A new recycling system should be implemented in developing countries and in new constructions. A system based on recycling and use of resources would be much more advantageous both from an economic and environmental point of view.
Creative Commons Attribution 4.0 International License

For possible submissions Click Here

\section{Submit Article}

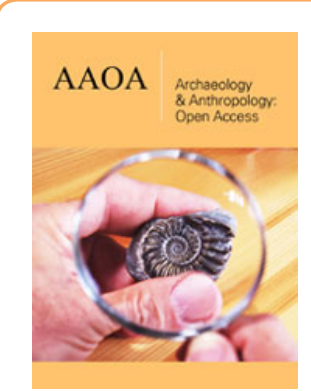

\section{Archaeology \& Anthropology: Open Access}

\section{Benefits of Publishing with us}

- High-level peer review and editorial services

- Freely accessible online immediately upon publication

- Authors retain the copyright to their work

- Licensing it under a Creative Commons license

- Visibility through different online platforms 